ACINETOBACTER BAUMANNII: PACПPOCTPAHEHHOCTЬ, СПЕКTP И ДИНАМИКА АНТИБИОТИКОРЕЗИСТЕНТНОСТИ, ЧУВСТВИТЕЛЬНОСТЬ К

\title{
КОМБИНАЦИЯМ АНТИБИОТИКОВ
}

'Тапальский Д. В. (tapalskiy@gsmu.by),_Бонда H. A. (bondana8448@gmail.com)

'УО «Гомельский государственный медицинский университет», Гомель, Беларусь

2 ГУ «Гомельский областной центр гигиены, эпидемиологии и общественного здоровья», Гомель, Беларусь

Цель. Изучить спектр и динамику антибиотикорезистентности Acinetobacter bauтаппіi, оценить механизмы устойчивости к карбапенемам и чувствительность к комбинациям антибиотиков.

Материал и методы. Для 305 клинических изолятов А. bаитаппіi определена чувствительность к антибиотикам автоматизированным методом. Детекиия генов карбапенемаз выполнена методом ПЦР в реальном времени. Чувствительность к комбинациям антибиотиков определена методом тестирования бактерицидности разных комбинаций.

Bыводы. Показано увеличение доли A.bauтаппіi в этиологической структуре инфекционной патологии. Отмечено увеличение антибиотикорезистентности. Выявлено наличие генов карбапенемаз ОХА-40. Не обнаружено изолятов, устойчивых к колистину. Комбинации меропенем-колистин, амикацин-колистин, левофлоксацин-колистин проявляли бактерицидную активность в отношении 100\% изолятов.

Ключевые слова: Acinetobacter baumannii, антибиотикорезистентность, меропенем, колистин, сульбактам, карбапенемазы, комбинации антибиотиков.

\section{Введение}

Acinetobacter baumannii - условно-патогенный микроорганизм, вызывающий инфекционные заболевания на фоне иммуносупрессии. У пациентов отделений реанимации и интенсивной терапии, травматологических и ожоговых отделений ацинетобактеры могут вызывать пневмонию, инфекции кровотока, катетер-ассоциированные и раневые инфекции, инфекции мочевыводящих путей [1]. С начала 2000-х годов во многих странах мира отмечается увеличение частоты возникновения ацинетобактерных инфекций, сопровождающихся быстрым распространением устойчивости возбудителей к антимикробным препаратам (АМП) $[1,2]$. Для определения уровней антибиотикорезистентности ацинетобактеров используются международные согласительные критерии: мультирезистентность (MDR - multidrug resistance) - нечувствительность по крайне мере к одному АМП в трех и более категориях АМП, экстремальная резистентность (XDR - extensively drug resistance) - нечувствительность по крайне мере к одному АМП во всех категориях АМП, за исключением 1-2 категорий, панрезистентность (PDR pandrug resistance) - нечувствительность ко всем AМП во всех категориях [3]. Важной причиной развития MDR и XDR у A.baumannii является продукция $\beta$-лактамаз класса $\mathrm{D}$, способных разрушать карбапенемы (карбапенемазы ОХА-23, OXA-40, OXA-56), а также метало- $\beta$-лактамаз (МБЛ) [4, 5]. Продукция карбапенемаз часто ассоциирована с множественной устойчивостью к АМП разных групп - цефалоспоринам, фторхинолонам, аминогликозидам. В настоящее время только полимиксины сохраняют приемлемую микробиологическую активность в отношении многих карбапенемрезистентных штаммов A.baumannii [6].
Для лечения инфекций, вызванных XDR и PDR A.baumannii, широко используется комбинированная антибиотикотерапия. Основной ее целью является достижение синергидного эффекта в отношении устойчивых бактериальных патогенов [7]. Микробиологическая эффективность комбинаций АМП трудно прогнозируема, что связано с разными сочетаниями механизмов антибиотикорезистентности. Поэтому для подбора эффективных комбинаций АМП целесообразно проводить определение чувствительности у XDR и PDR изолятов, выделенных от конкретного пациента $[8,9]$. Накоплен опыт использования метода тестирования бактерицидности разных комбинаций (Multiple combination bactericidal testing, MCВТ) для поиска бактерицидных комбинаций в отношении карбапенемаза-продуцирующих A.baumannii с целью коррекции антибактериальной терапии $[8,10]$.

Цель исследования - изучить спектр и динамику антибиотикорезистентности штаммов A.baumannii, выделенных от госпитализированных пациентов, оценить генетические механизмы устойчивости к карбапенемам и чувствительность к комбинациям АМП.

\section{Материал и методы}

На базе микробиологической лаборатории Гомельского областного центра гигиены, эпидемиологии и общественного здоровья организована система микробиологического мониторинга, заключающаяся в выявлении и типировании клинических изолятов микроорганизмов с XDR и PDR. При проведении рутинных микробиологических исследований в 2012-2015 гг. из клинического материала пациентов, госпитализированных в 9 учреждениях здравоохранения г. Гомеля, было выделено 305 изолятов A.baumannii.

Видовая идентификация микроорганизмов 
проводилась с использованием ручных коммерческих тест-систем API 20NE (bioMérieux, Франция) или при помощи автоматического микробиологического анализатора VITEK 2 Compact на идентификационных картах VITEK 2 GN (bioMérieux, Франция). Определение чувствительности к АМП выполнено на анализаторе VITEK 2 Compact с использованием диагностических карт AST-N 115 и AST-XN-05. Для ввода, хранения и анализа микробиологической информации использовали программу WHONET 5.6 (ВО3, Женева). Анализировали чувствительность к 10 АМП: ампициллину/сульбактаму, цефтазидиму, цефотаксиму, цефепиму, меропенему, имипенему, гентамицину, амикацину, тобрамицину, ципрофлоксацину.

Для выполнения дальнейших молекулярно-генетических исследований и определения чувствительности к комбинациям АМП 28 клинических изолятов A.baumannii, выделенных в 2014 г., были помещены в рабочую коллекцию и хранились в триптон-соевом бульоне (BD, США) с добавлением 30\% глицерина в замороженном состоянии при $-70^{\circ} \mathrm{C}$. Поскольку определение чувствительности к колистину с помощью автоматизированных систем не позволяет получать надежные результаты $[11,12]$, для получения истинных значений минимальных подавляющих концентраций (МПК) дополнительно был использован метод последовательных микроразведений в бульоне Мюллера-Хинтона (BD, США). Определяли также МПК для меропенема, сульбактама и тигециклина. Тестирование проводили в стерильных круглодонных 96-луночных полистироловых планшетах (Sarstedt, Германия) в соответствии с ISO 20776-1:2006 [13]. При учете и интерпретации результатов руководствовались стандартами EUCAST [14]. Качество исследований контролировали штаммами E.coli ATCC 25922 и P.aeruginosa ATCC 27853.

Детекцию генов ОХА-карбапенемаз (группы OXA-23, OXA-40, ОХА-56) и металло- $\beta$-лактамаз (группы IMP, VIM, NDM) выполняли методом полимеразной цепной реакции в реальном времени с использованием диагностических наборов АмплиСенс MDR A.b.-ОХА и АмплиСенс MDR MBL-FL (Центральный научно-исследовательский институт эпидемиологии Роспотребнадзора, г. Москва). Выделение бактериальной ДНК проводили с помощью температурного лизиса в ТЕ-буфере. Амплификацию с гибридизационно-флуоресцентной детекцией в peжиме «реального времени» на амплификаторе RotorGene 3000 (Corbett Research, Австралия), анализ и интерпретацию полученных результатов выполняли в соответствии с инструкциями производителя диагностических наборов.

Определение чувствительности к комбинациям АМП выполняли модифицированным методом тестирования бактерицидности разных комбинаций [15] с нашими модификациями [16]. В составе двойных комбинаций тестировали АМП, взятые в пороговых фармакокинетических/фармакодинамических (ФК/ФД) концентрациях: меропенем - 8 мкг/мл, амикацин - 16 мкг/мл, ле- вофлоксацин - 1 мкг/мл, сульбактам - 4 мкг/мл, тигециклин - 0,5 мкг/мл, колистин - 2 мкг/мл.

Готовили рабочие растворы АМП, содержащие тестируемые концентрации, увеличенные в 10 раз. В качестве разбавителя использовали бульон Мюллера-Хинтона (МХБ). Комбинацию из двух АМП готовили в лунках стерильных 96-луночных полистироловых планшетов (Sarstedt, Германия), смешивая по 10 мкл рабочих растворов АМП 1 и АМП 2 и добавляя 80 мкл суспензии исследуемой бактериальной культуры, приготовленной в МХБ и содержащей $6 \div 8$ х $10^{5} \mathrm{Mл}^{-1}$ бактериальных клеток. Для тестирования одной культуры использовали горизонтальный ряд из 12 лунок, при этом в лунки 1-11 вносили разные комбинации из двух АМП, лунка 12 не содержала АМП и использовалась в качестве контроля роста культуры. После инокуляции планшеты инкубировали 48 ч при температуре $35^{\circ} \mathrm{C}$. После инкубации делали количественный высев 10 мкл содержимого из каждой лунки на сектор плотной питательной среды, посевы инкубировали $18-24$ ч при $35^{\circ} \mathrm{C}$. Оценивали микробиологическую эффективность каждой из тестируемых комбинаций АМП. Бактерицидная активность определялась как снижение на 99,9\% и более количества микробных клеток в присутствии АМП по сравнению с исходным инокулятом (отсутствие микробного роста на соответствующем секторе либо рост не более 1 колонии микроорганизмов).

\section{Результаты и обсуждение}

Из 305 выделенных в 2012-2015 гг. изолятов A.baumannii 109 (35,7\%) были выделены от пациентов отделений хирургии, $66(21,6 \%)$ - peaнимационных отделений, 52 (17,0\%) - ожоговых отделений, $36(11,8 \%)$ - урологических отделений, $25(8,2 \%)$ - отделений терапевтического профиля, 17 (5,6\%) - онкологических отделений. Отмечено неуклонное увеличение частоты выделения A.baumannii от госпитализированных пациентов. Так, если в 2012 г. выделено 43 изолята A.baumannii (или $4,0 \pm 0,6 \%$ от всех положительных клинических образцов), то в 2013 г. уже 69 изолятов $(4,5 \pm 0,5 \%)$, в 2014 г. $-78(5,0 \pm 0,5 \%)$, в 2015 г. - $115(5,7 \pm 0,5 \%, \mathrm{p}<0,05$ для сравниваемого показателя 2012 г.). Из раневого отделяемого было выделено 190 изолятов A.baumannii $(62,3 \%)$, из мокроты - 58 изолятов $(19,0 \%)$, из мочи - 44 изолята $(14,4 \%)$. Только 2 изолята $(0,7 \%)$ были выделены из крови, что говорит о низком инвазивном потенциале возбудителя.

Вместе с неуклонным увеличением доли A.baumannii в этиологии заболеваний отмечен также неуклонный рост их резистентности к основным AMП с формированием XDR. Результаты определения чувствительности A.baumannii к 10 АМП представлены на рисунке 1. Для меропенема, имипенема, гентамицина, амикацина, ципрофлоксацина отмечен статистически значимый рост антибиотикорезистентности $(\mathrm{p}<0,05$ для сравниваемых показателей 2012 и 2015 гг.). Устойчивость A.baumannii к цефалоспоринам, карбапенемам, аминогликозидам и ципрофлок- 
сацину преодолела рубеж 80\% и приблизилась к 100\% нечувствительных изолятов. Устойчивость A.baumannii к меропенему и имипенему оказалась существенно выше, чем в предыдущих исследованиях, проведенных в 2007-2012 гг. в Беларуси и Российской Федерации [2], но в целом соответствовала результатам, полученным в многоцентровых исследованиях 2013-2014 гг. «МАРАФОН» [6] и CAESAR [17]. Сульбактам-содержащие препараты широко использовались для лечения инфекций, вызванных устойчивыми к штаммами A.baumannii, однако в настоящем исследовании выявлено увеличение устойчивости к ампициллину/сульбактаму с $48,5 \%$ нечувствительных изолятов в 2012 г. до 64,3\% в 2015 г.

Для 28 изолятов A.baumannii, выделенных в 2014 г., проводилось выявление генов карбапенемаз. У всех из них обнаружены гены карбапенемаз ОХА-40. Присутствия генов МБЛ (IMP, VIM и NDM) не установлено. Данные о чувствительности к меропенему, сульбактаму, тигециклину и колистину для этих изолятов представлены в таблице. Чувствительными к колистину были $100,0 \%$ изолятов, к тигециклину $-92,9 \%$, к сульбактаму - только 25,0\%. Все изоляты были устойчивыми к меропенему (МПК50 - 128 мкг/мЛ, МПК90 256 мкг/мл).

Результаты определения чувствительности к комбинациям АМП для 28 карбапенемаза-продуцирующих изолятов A.baumannii представлены на рисунке 2. Отмечена бактерицидная активность в отношении 100\% включенных в исследование изолятов для трех комбинаций с включением колистина (меропенем-колистин, амикацин-колистин, левофлоксацин-колистин). Несмотря на выявленную у большинства изолятов A.baumannii, чувствительность к тигециклину, комбинации с его включением не проявляли бактерицидной активности, что может быть связано с бактериостатическим типом действия препарата. Исключение - бактерицидная активность комбинации тигециклин-колистин $\quad(89,3 \%$ чувствительных

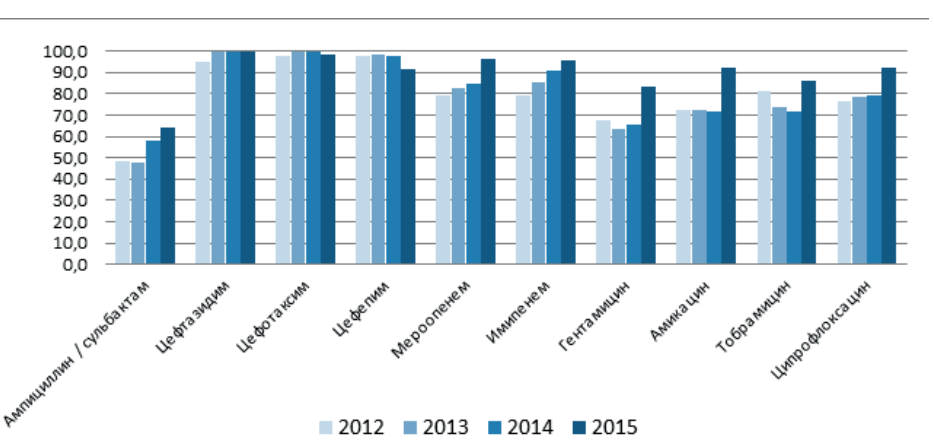

Рисунок 1. - Динамика антибиотикорезистентности среди госпитальных изолятов А.bаитаппіi, выделенных в 2012-2015 z2. (\% нечувствительных изолятов)

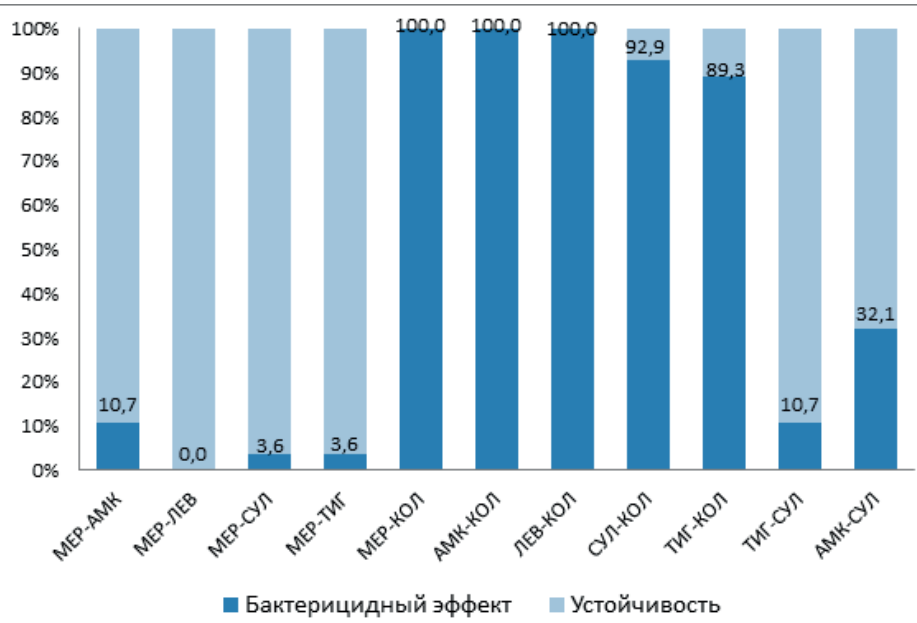

Примечание - МЕР - меропенем, АМК - амикацин, ЛЕВ - левофлоксацин, СУЛ - сульбактам, ТИГ - тигециклин, КОЛ - колистин

\section{Рисунок 2. - Эффективность комбинаций АМП в отночении карбапенемаза-продуцирующих изолятов А.bаuтапnii, выделенных в 20142.}

изолятов). Все комбинации с включением меропенема, за исключением комбинации меропенем-колистин, не проявляли бактерицидной активности.

\section{Выводы}

Выявлено увеличение доли A.baumannii в этиологической структуре инфекционной патологии в соматических и хирургических стационарах с 4,0 $00,6 \%$ в 2012 г. до $5,7 \pm 0,5 \%$ в 2015 г. $(\mathrm{p}<0,05)$.

Таблица - Чувствительность к антибиотикам карбапенемаза-продуцирующих A.baumannii (n=28)

\begin{tabular}{|c|c|c|c|c|c|c|c|c|c|c|c|c|c|c|c|c|}
\hline \multirow[t]{2}{*}{ Антибиотик } & \multicolumn{11}{|c|}{ \% изолятов со значением МПК, мкг/мл } & \multicolumn{3}{|c|}{$\begin{array}{c}\text { \% изолятов по } \\
\text { категориям* }\end{array}$} & \multicolumn{2}{|c|}{$\begin{array}{l}\text { МПК, } \\
\text { мкг/мЛ }\end{array}$} \\
\hline & 0,25 & 0,5 & 1 & 2 & 4 & 8 & 16 & 32 & 64 & 128 & 256 & Ч & УР & $\mathrm{P}$ & $\mathrm{M \Pi K}_{50}$ & $\mathrm{M \Pi K}_{90}$ \\
\hline Меропенем & & & & & & & & & 17,9 & 60,7 & 21,4 & & & 100 & 128 & 256 \\
\hline Сульбактам & & & & 7,1 & 17,9 & 10,7 & 28,6 & 25,0 & 10,7 & & & 25,0 & & 75,0 & 16 & 32 \\
\hline Тигециклин & 3,6 & 21,4 & 67,9 & 7,1 & & & & & & & & 92,9 & & 7,1 & 1 & 1 \\
\hline Колистин & 14,3 & 53,6 & 32,1 & & & & & & & & & 100 & & & 0,5 & 1 \\
\hline
\end{tabular}

*Примечание: Ч-чувствительные, УР-умеренно резистентные, $P$ - резистентные 
Отмечено увеличение устойчивости A.baumannii к большинству АМП (для меропенема, имипенема, гентамицина, амикацина, ципрофлоксацина $\mathrm{p}<0,05$ для сравниваемых показателей 2012 и 2015 гг.) с развитием XDR.

Устойчивость к имипенему и меропенему обусловлена присутствием генов карбапенемаз ОХА-40. С помощью метода микроразведений в бульоне среди продуцентов карбапенемаз не выявлено изолятов, устойчивых к колистину (МПК50 - 0,5 мкг/мл, МПК90 - 1 мкг/мл).

Полученные данные позволяют прогнозировать дальнейшее увеличение резистентности A.baumannii к большинству AМП с формированием XDR и даже PDR, таким образом, для лечения ацинетобактерных инфекций может

\section{Литература}

1. Acinetobacter : микробиологические, патогенетические и резистентные свойства / И. В. Чеботарь [и др.] // Вестник Российской академии медицинских наук. - 2014 - T. 69, № 9-10. - C. 39-50. - doi:10.15690/vramn.v69i910.1130 .

2. Особенности резистентности Acinetobacter baumannii к карбапенемам в Республике Беларусь / Ю. Л. Горбич [и др.] // Здравоохранение. - 2011. - № 5. -С. 25-30.

3. Multidrug-resistant, extensively drug-resistant and pandrug-resistant bacteria: an international expert proposal for interim standard definitions for acquired resistance / A. P. Magiorakos [et al.] // Clin. Microbiol. Infect. - 2012. - Vol. 18, № 3. - P. 268-281. - doi: 10.1111/j.1469-0691.2011.03570.x.

4. Bonnin, R. A. Screening and deciphering antibiotic resistance in Acinetobacter baumannii : a state of the art / R A. Bonnin, P. Nordmann, L. Poirel // Expert Rev. Anti. Infect. Ther. - 2013. - Vol. 11, № 6. - P. 571-583. - doi: 10.1586/ eri.13.38.

5. Тапальский, Д. В. Карбапенемазы грамотрицательных бактерий: распространение и методы детекции / Д. В. Тапальский, В. А. Осипов, С. В. Жаворонок // Медицинский журнал. - 2012. - № 2. - С. 10-15.

6. Антибиотикорезистентность нозокомиальных штаммов Acinetobacter spp. в стационарах России : результаты многоцентрового эпидемиологического исследования «МАРАФОН» 2013-2014 / Сухорукова М.В.[и др.] // Клиническая микробиология и антимикробная химиотерапия. - 2017. - Т. 19, № 1. - С. 42-48.

7. Zavascki, A. P. Combination therapy for carbapenemresistant Gram-negative bacteria / A. P. Zavascki, J. B. Bulitta, C. B. Landersdorfer // Expert Rev. Anti. Infect. Therapy. - 2013. - Vol. 11, № 12. - P. 1333-1353. - doi: 10.1586/14787210.2013.845523.

8. From Bench-Top to Bedside: A Prospective In Vitro Antibiotic Combination Testing (iACT) Service to Guide the Selection of Rationally Optimized Antimicrobial Combinations against Extensively drug Resistant (XDR) Gram Negative Bacteria (GNB) / Y. Cai [et al.] // PLoS ONE. - 2016. - Vol. 11, № 7. - P. e0158740. - doi: 10.1371/journal.pone.0158740.

9. Treatment options for infections caused by carbapenemresistant Enterobacteriaceae: can we apply "precision medicine" to antimicrobial chemotherapy? / F. Perez [et al.] // Expert Opin. Pharmacother. - 2016. - Vol. 17, № 6. - P. 761-781. - doi: $10.1517 / 14656566.2016 .1145658$. потребоваться проведение комбинированной антибиотикотерапии.

C помощью модифицированного метода MCВТ в отношении всех протестированных клинических изолятов A.baumannii выявлено по 3 и более комбинаций АМП с бактерицидной активностью. Комбинации с включением колистина (меропенем-колистин, амикацин-колистин, левофлоксацин-колистин) проявляли бактерицидную активность в отношении 100\% протестированных изолятов.

Требуется внедрение программ инфекционного контроля для ограничения распространения в госпитальной среде штаммов A.baumannii c XDR- и PDR-фенотипами.

10. Extensively drug-resistant Acinetobacter baumannii in a Thai hospital: a molecular epidemiologic analysis and identification of bactericidal Polymyxin B-based combinations / J. Teo [et al.] // Antimicrob. Resist. Infect. Control. - 2015. Vol. 4, № 1. - P. 2. - doi: 10.1186/s13756-015-0043-x.

11. Colistin and Polymyxin B Susceptibility Testing for Carbapenem-Resistant and mcr-Positive Enterobacteriaceae: Comparison of Sensititre, MicroScan, Vitek 2, and Etest with Broth Microdilution / K. L. Chew [et al.] // J. Clin. Microbiol. - 2017. - Vol. 55, № 9. - P. 2609-2616. - doi: 10.1128/ JCM.00268-17.

12. Vasoo, S. Susceptibility testing for the polymyxins : Two steps back, three steps forward? / S. Vasoo // J. Clin. Microbiol. - 2017. - Vol. 55, № 9. - P. 2573-2582. - doi: 10.1128/JCM.00888-17.

13. ISO 20776-1:2006 Clinical laboratory testing and in vitro diagnostic test systems - Susceptibility testing of infectious agents and evaluation of performance of antimicrobial susceptibility test devices [Electronic resource]. - 1st ed. Switzerland, 2006. - Pt. 1 : Reference method for testing the in vitro activity of antimicrobial agents against rapidly growing aerobic bacteria involved in infectious diseases. - 19 p. - Mode of access: https://www.iso.org/standard/41630.html. - Date of access: 30.05.2018.

14. Breakpoint tables for interpretation of MICs and zone diameters. Ver. 8.0 2018 [Electronic resource] / European Committee on Antimicrobial Susceptibility testing (EUCAST). - Mode of access: http://www.eucast.org/clinical_breakpoints/. - Date of access: 30.05.2018.

15. Multiple combination bactericidal antibiotic testing for patients with cystic fibrosis infected with Burkholderia cepacia / S. D. Aaron [et al.] // Am. J. Respir. Crit. Care Med. 2000. - Vol. 161, № 4 (pt. 1). - P. 1206-1212. - doi: 10.1164/ ajrccm.161.4.9907147.

16. Методы определения чувствительности к комбинациям антибиотиков грамотрицательных бактерий с экстремальной и полной антибиотикорезистентностью : инструкция по применению № 002-0517 : утв. М-вом здравоохранения Респ. Беларусь 31.08.2017 / Учреждениеразработчик УО «ГомГМУ»; авт.: Д. В. Тапальский, Л. В. Лагун. - Гомель, 2017. - 27 с.

17. Central Asian and Eastern European surveillance of antimicrobial resistance. Annual report 2016 [Electronic resource] / Word Health Organization - Mode of access: http://www.euro.who.int/ data/assets/pdf file/0009/323568/ CAESAR-Annual-report-2016.pdf?ua=1. - Date of access: 30.05.2018. 


\section{References}

1. Chebotar IV, Lazareva AV, Masalov YaK, Mikhailovich VM, Mayanskiy NA. Acinetobacter: mikrobiologicheskie, patogeneticheskie i rezistentnye svojstva [Acinetobacter: microbiological, pathogenetic and resistant properties]. Vestnik Rossijskoj akademii medicinskih nauk [Bulletin of the Russian Academy of Medical Sciences]. 2014;69(9-10):39-50. doi:10.15690/vramn.v69i9-10.1130 (Russian).

2. Gorbich YuL, Karpov IA, Martinovich AA, Levshina NN. Osobennosti rezistentnosti Acinetobacter baumannii k karbapenemam v Respublike Belarus [Peculiar features of Acinetobacter baumannii resistance to carbapenems in the Republic of Belarus]. Zdravoohranenie [Health care]. 2011;5:25-30. (Russian).

3. Magiorakos AP, Srinivasan A, Carey RB, Carmeli Y, Falagas ME, Giske CG, Harbarth S, Hindler JF, Kahlmeter G, Olsson-Liljequist B, Paterson DL, Rice LB, Stelling J, Struelens MJ, Vatopoulos A, Weber JT, Monnet DL. Multidrug-resistant, extensively drug-resistant and pandrug-resistant bacteria: an international expert proposal for interim standard definitions for acquired resistance. Clin. Microbiol. Infect. 2012;18(3):268281. doi: 10.1111/j.1469-0691.2011.03570.x

4. Bonnin RA, Nordmann P, Poirel L. Screening and deciphering antibiotic resistance in Acinetobacter baumannii: a state of the art. Expert Rev. Anti. Infect. Ther. 2013;11(6):571-583. doi: 10.1586/eri.13.38.

5. Tapalski DV, Osipov VA, Zhavoronok SV. Karbapenemazy gramotricatel'nyh bakterij: rasprostranenie i metody detekcii [Carbapenemases of gram-negative pathogens: spread and methods of detection]. Medicinskij zhurnal [Medical journal]. 2012;2:10-15. (Russian).

6. Suhorukova MV, Jejdelshtejn MV, Skleenova EJu, Ivanchik NV, Shek EA, Dehnich AV, Kozlov RS. Antibiotikorezistentnost nozokomialnyh shtammov Acinetobacter spp. v stacionarah Rossii: rezultaty mnogocentrovogo jepidemiologicheskogo issledovanija «MARAFON» 2013-2014 [Antimicrobial resistance of nosocomial Acinetobacter spp. isolates in Russia: results of multicenter epidemiological study «MARATHON» 2013-2014]. Klinicheskaja mikrobiologija i antimikrobnaja himioterapija [Clinical Microbiology and Antimicrobial Chemotherapy]. 2017;19(1):42-48. (Russian).

7. Zavascki AP, Bulitta JB, Landersdorfer CB. Combination therapy for carbapenem-resistant Gram-negative bacteria. Expert Rev. Anti. Infect. Ther. 2013;11(12):1333-1353. doi: 10.1586/14787210.2013.845523.

8. Yiying C, Nathalie GC, Tze-Peng L, Jocelyn Qi-Min T, Winnie L, Asok K, Tse-Hsien K, Thuan-Tong T, Andrea LK. From Bench-Top to Bedside: A Prospective In Vitro Antibiotic Combination Testing (iACT) Service to Guide the Selection of Rationally Optimized Antimicrobial Combinations against Extensively Drug Resistant (XDR) Gram Negative Bacteria
(GNB). PLoS ONE 2016;11(7):e0158740. doi: 10.1371/journal. pone. 0158740 .

9. Perez F, El Chakhtoura NG, Papp-Wallace KM, Wilson BM, Bonomo RA. Treatment options for infections caused by carbapenem-resistant Enterobacteriaceae: can we apply "precision medicine" to antimicrobial chemotherapy? Expert Opin. Pharmacother. 2016;17(6):761-781. doi: 10.1517/14656566.2016.1145658.

10. Teo J, Lim TP, Hsu LY, Tan TY, Sasikala S, Hon PY, Kwa AL, Apisarnthanarak A. Extensively drug-resistant Acinetobacter baumannii in a Thai hospital: a molecular epidemiologic analysis and identification of bactericidal Polymyxin B-based combinations. Antimicrob. Resist. Infect. Control. 2015;4(1):2. doi: 10.1186/s13756-015-0043-x.

11. Chew KL, La MV, Lin RTP, Teo JWP. Colistin and Polymyxin B Susceptibility Testing for Carbapenem-Resistant and mcr-Positive Enterobacteriaceae: Comparison of Sensititre, MicroScan, Vitek 2, and Etest with Broth Microdilution. J. Clin. Microbiol. 2017;55(9):2609-2616. doi: 10.1128/JCM.0026817.

12. Vasoo S. Susceptibility testing for the polymyxins: Two steps back, three steps forward? J. Clin. Microbiol. 2017;55(9):2573-2582. doi: 10.1128/JCM.00888-17.

13. ISO 20776-1:2006 «Clinical laboratory testing and in vitro diagnostic test systems - Susceptibility testing of infectious agents and evaluation of performance of antimicrobial susceptibility test devices». Pt. 1, Reference method for testing the in vitro activity of antimicrobial agents against rapidly growing aerobic bacteria involved in infectious diseaes [Internet]. $1^{\text {st }}$ ed. Switzerland, 2006. 19 p. Available from: https://www.iso.org/standard/41630.html.

14. European Committee on Antimicrobial Susceptibility testing (EUCAST). Breakpoint tables for interpretation of MICs and zone diameters. Ver. 8.02018 [Internet]. Available from: http://www.eucast.org/clinical_breakpoints/.

15. Aaron SD, Ferris W, Henry DA, Speert DP, Macdonald NE. Multiple combination bactericidal antibiotic testing for patients with cystic fibrosis infected with Burkholderia cepacia. Am. J. Resp. Crit. Care Med. 2000;161(4 Pt 1):1206-1212. doi: 10.1164/ajrccm.161.4.9907147.

16. Tapalskij DV, Lagun LV; UO "Gomelskij gosudarstvennyj medicinskij universitet". Metody opredelenija chuvstvitelnosti k kombinacijam antibiotikov gramotricatelnyh bakterij $\mathrm{s}$ jekstremalnoj i polnoj antibiotikorezistentnostju [Methods for determining sensitivity to combinations of antibiotics of gram-negative bacteria with extensively drug resistance and pandrug resistance]. BY instructions 002-0517. 2017. Aug 31. (Russian).

17. Word Health Organization. Central Asian and Eastern European surveillance of antimicrobial resistance. Annual report 2016 [Internet]. Available from: http://www.euro.who. int/__data/assets/pdf_file/0009/323568/CAESAR-Annualreport-2016.pdf?ua $=1$.

\section{ACINETOBACTER BAUMANNII: PREVALENCE, SPECTRUM AND DYNAMICS OF ANTIMICROBIAL RESISTANCE, SUSCEPTIBILITY TO ANTIBIOTIC COMBINATIONS ${ }^{7}$ Tapalski D. V., ${ }^{2}$ Bonda N. A. \\ 'Educational Institution «Gomel State Medical University», Gomel, Belarus \\ ${ }^{2}$ State Institution «Gomel Regional Center for Hygiene, Epidemiology and Public Health», Gomel, Belarus}

Objective. To study the spectrum and dynamics of antimicrobial resistance to Acinetobacter baumannii, to assess the resistance mechanisms to carbapenems and antibiotic combinations susceptibility.

Material and Methods. The antibiotic susceptibility of 305 A.baumannii clinical isolates was determined by an 
automated method. Carbapenemase genes detection was performed by real-time PCR method. Multiple combination bactericidal testing method is used for determination of antibiotic combinations susceptibility.

Conclusions. The proportion of A.baumannii in the etiological structure of infectious pathology is increased. An increase in antimicrobial resistance was noted. The presence of OXA-40 carbapenemase genes was detected. No isolates resistant to colistin were found. Meropenem-colistin, amikacin-colistin and levofloxacin-colistin combinations were bactericidal for $100 \%$ of the isolates.

Keywords: Acinetobacter baumannii, antimicrobial resistance, meropenem, colistin, sulbactam, carbapenemases, antibiotic combinations.

\section{С. В. ЛЕЛЕВИЧ, Т. П. СТЕМПЕНЬ}

\section{ИЗОСЕРОЛОГИЧЕСКИЕ ИССЛЕДОВАНИЯ В КЛИНИКЕ}

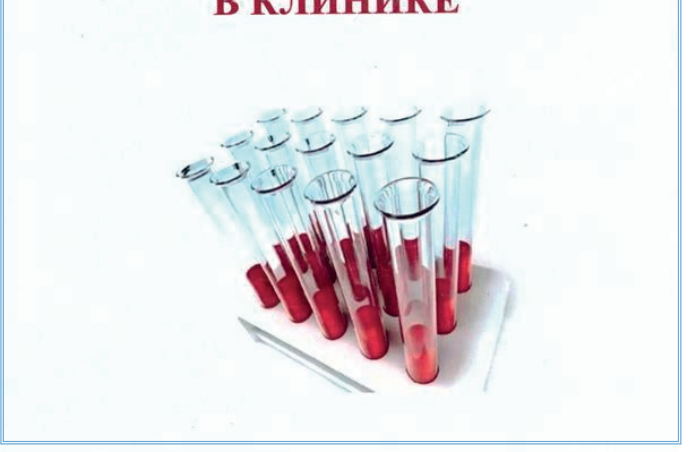

Лелевич, С. В. Изосерологические исследования в клинике : пособие для студентов медико-диагностического факультета (специальность 1-79 0104 "Медикодиагностическое дело") / С. В. Лелевич, Т. П. Стемпень ; Министерство здравоохранения Республики Беларусь, Учреждение образования "Гродненский государственный медицинский университет", Кафедра клинической лабораторной диагностики и иммунологии. - Гродно : ГрГМУ, 2018. - 162 с. : табл. - Библиогр.: с. 161-162. - ISBN 978985-558-927-4.

В пособии изложена информащия об основных вопросах иммуногематологии. Обсуждаются вопросы, касающиеся основных антигенных систем крови, их практического значения. Приводится информачия о методах определения групп крови по системе $A B O$ и резус-фактора. Затрагиваются некоторые аспекты гемотрансфузий.

Пособие предназначено для студентов медико-диагностического факультета, а также специалистов клинической лабораторной диагностики. 